\section{INTERACTIONS OF ACIDIC HERBICIDES BENTAZON AND DICAMBA WITH ORGANOCLAYS}

\author{
María José Carrizosa, William C. Koskinen,** \\ and María del Carmen Hermosín
}

\begin{abstract}
We determined the sorption mechanism of the acidic herbicides bentazon [3-(1-methylethyl)-1H-2,1,3-benzothiadiazin-4(3H)-one 2,2-dioxide] and dicamba (3,6-dichloro-2-methoxybenzoic acid) on two organoclays, octadecylammonium (ODA)- and hexadecyltrimethylammonium (HDTMA)-exchanged Arizona montmorillonite (SAz-1), as part of a study to determine their potential use as sorbent materials for ionizable organic pollutants. To determine the mechanisms involved in the sorption process, herbicide-organoclay complexes were characterized by $x$-ray diffraction (XRD) and Fourier transform infrared spectroscopy (FTIR). In general, the $d_{001}$ values of SAz-HDTMA and SAz-ODA organoclays expanded after herbicide saturation, indicating interlayer sorption of the herbicide. Also, FTIR spectroscopic studies suggested weak hydrophobic interactions between these herbicides and the interlayer organic phase of the organoclays. However, $\mathrm{H}$ bonding between these herbicides and the monosubstituted amino group in SAz-ODA reinforced the strength of the hydrophobic interactions resulting in nonreadily reversible sorption on that organoclay. These results suggest that organoclays can be used to remove this type of pollutants from water or soils.
\end{abstract}

$\mathrm{O}$ RGANOCLAYS HAVE BEEN SHOWN to be good sorbents in removing hydrophobic organic chemicals and polar pesticides from water (Boyd et al., 1988; Lee et al., 1989; Hermosin and Cornejo, 1992, 1993; Hermosin et al., 1995; Zhao et al., 1996; Pantani et al., 1997; Xu et al., 1997; Celis et al., 1999). Hydrophobic and polar interactions between the pesticide and the alkyl chains of the $\mathrm{OCl}$ and mineral surfaces, respectively, can reduce pesticide mobility in soil. Recent studies further suggest that OCls can be advantageously used to restore soil and water contaminated with polar herbicides (SociasViciana et al., 1998; Aguer et al., 2000; Carrizosa et al., 2000, 2001). Before organoclays can be used in protection and restoration of soils and waters contaminated with organic pollutants, information is needed on specific sorbent-pesticide interactions, including information on desorption (Hermosin and Cornejo, 1992, 1993; Celis et al., 1999).

Previous research has reported information about the sorption behavior of several organoclays for the acidic

M.J. Carrizosa and W.C. Koskinen, USDA-ARS, Soil and Water Management Research Unit, 1991 Upper Buford Cir., Rm. 439, St. Paul, MN 55108; M. del Carmen Hermosín, Instituto de Recursos Naturales y Agrobiología de Sevilla, CSIC, P.O. Box 1052, 41080 Sevilla, Spain. Received 23 Oct. 2003. *Corresponding author (koskinen@umn.edu).

Published in Soil Sci. Soc. Am. J. 68:1863-1866 (2004).

(C) Soil Science Society of America

677 S. Segoe Rd., Madison, WI 53711 USA herbicides such as bentazon, dicamba, imazamox, and picloram and their potential use as immobilizing agents in contaminated soils (Carrizosa et al., 2000, 2001; Celis et al., 1999, 2002). Hydrophobic interactions with polar contributions were suggested to be responsible for sorption of both herbicides on organoclays, with the magnitude of sorption dependent on the nature of the saturating alkylammonium cation. The objective of this study was to determine the possible mechanisms involved in the sorption of bentazon and dicamba on ODA and HDTMAexchanged montmorillonite by XRD and FTIR.

\section{Materials and Methods}

Bentazon (97\% pure) is a crystalline solid with a solubility of $570 \mathrm{mg} \mathrm{L}^{-1}$ water $(2.08 \mathrm{mM})\left(20^{\circ} \mathrm{C}\right)$ and pKa 2.3 (Worthing and Hance, 1991). Bentazon was kindly supplied by BASF (Research Triangle Park, NC). Dicamba (99\% pure) is a crystalline solid with a solubility of $6.5 \mathrm{~g} \mathrm{~L}^{-1}$ water $(29.4 \mathrm{mM})$ $\left(25^{\circ} \mathrm{C}\right)$, and $\mathrm{pKa} 1.95$ (Worthing and Hance, 1991). Pure analytical dicamba was purchased from Chem Service (West Chester, PA).

Arizona montmorillonite (SAz-1), supplied by the Clay Mineral Repository of the Clay Minerals Society (Aurora, $\mathrm{CO}$ ), was used as received in the preparation of the organoclays. SAz1 was Ca saturated and has a cation exchange capacity (CEC) of $120 \mathrm{cmol} \mathrm{kg}^{-1}$ (Van Olphen and Fripiat, 1979). The organoclays were prepared as previously described (Carrizosa et al., 2000, 2001). In brief, $100 \mathrm{~g}$ of the mineral clay was treated with an ethanol/water (50:50) solution of the quaternary (HDTMA) or primary (ODA) alkylammonium chloride/bromide containing an amount of cation equivalent to $100 \%$ of the sample CEC. The suspensions were shaken, centrifuged, washed with aqueous ethanol followed by deionized (DI) water until halide free, and then freeze dried. The physicochemical properties of the organoclays are shown in Table 1.

Herbicide saturated organoclays were prepared by five successive treatments of $20 \mathrm{mg}$ of the organoclays with $8 \mathrm{~mL}$ of a concentrated solution of the herbicides in DI water. The amount of herbicide sorbed after successive treatments of organoclays with the herbicide solutions was calculated from the sum of the decreases in herbicide solution concentrations after each successive treatment. The basal spacings of the organoclays-herbicide complexes were measured by x-ray in a Siemens D-5000 equipment (Siemens/Brukerans, Karlsruhe Germany) with $\mathrm{CuK} \alpha$ radiation on an oriented film supported on a glass-slide and a goniometer rate of $2^{\circ} \mathrm{min}^{-1}$. This film was prepared by depositing aliquots of approximately $2 \%$ methanol/water (50:50) suspensions. The samples were also analyzed by FTIR spectroscopy (Nicolet PC spectometer, Nicolet Instruments Corp., Madison, WI) on $\mathrm{KBr}$ disks.

\section{Results and Discussion}

At low solution concentrations, high sorption affinities of the acidic herbicides bentazon, dicamba, and picloram were previously found for SAz-1 saturated

Abbreviations: CEC, cation-exchange capacity; FTIR, Fourier transform infrared; HDTMA, hexadecyltrimethylammonium; ODA, octadecylammonium; XRD, x-ray diffraction. 
Table 1. Physicochemical properties and Freundlich constants of organoclays. $\dagger$

\begin{tabular}{|c|c|c|c|c|c|c|c|c|c|c|}
\hline \multirow[b]{2}{*}{ Sorbent } & \multirow[b]{2}{*}{ CEC } & & & & \multicolumn{2}{|c|}{ Bentazon } & \multicolumn{2}{|c|}{ Dicamba§ } & \multicolumn{2}{|c|}{ Picloram I } \\
\hline & & $\% \mathrm{OC}$ & ${ }_{0} \mathrm{OC}$ & $S \mathbf{d}_{001}$ & $\mathbf{K}_{\mathrm{f}}$ & $1 / n_{\mathrm{f}}$ & $\mathbf{K}_{\mathrm{f}}$ & $1 / n_{f}$ & $\mathbf{K}_{\mathrm{f}}$ & $1 / n_{f}$ \\
\hline & & & & $\mathbf{n m}$ & & & & & & \\
\hline SAz-HDTMA & 120 & 22.8 & 85 & 2.4 & 826 & 0.41 & 272 & 0.50 & 240 & \\
\hline SAz-ODA & 120 & 25.5 & 98 & 3.2 & 285 & 2.7 & 352 & 2.1 & 504 & 1.7 \\
\hline
\end{tabular}

with a large quaternary organic cation (HDTMA), while low sorption affinities were found for this clay saturated with a primary alkylammonium cation (ODA) (Carrizosa et al., 2000, 2001; Celis et al., 2002). It was suggested that hydrophobic interactions driving the sorption between herbicide molecules and organoclay would be predominant in the case of SAz-HDTMA, whereas polar herbicide-solvent interactions would predominate for SAz-ODA. This was supported by the slopes of the Freundlich sorption isotherms, where $1 / n_{\mathrm{f}} \ll 1.0$ for SAz-HDTMA and $1 / \mathrm{n}_{\mathrm{f}} \gg 1.0$ for SAz-ODA. Desorption isotherms for dicamba (Carrizosa et al., 2001), picloram (Celis et al., 2002), and bentazon (unpublished results) with SAz-HDTMA exhibited reversible sorption for the three herbicides, whereas there was hysteresis during desorption from SAz-ODA. Because of these differences in strengths of herbicide-organoclay interactions, these two organoclays were selected for the mechanistic studies.

The amounts of acidic herbicides sorbed after successive treatments of SAz-HDTMA and SAz-ODA with herbicide solutions, show the high sorption capacity of the organoclays for bentazon and dicamba (Table 2). In previous research, greater sorption was reported on SAz-HDTMA as compared with SAz-ODA (Carrizosa et al., 2000, 2001). The $\mathrm{d}_{001}$ values (Table 2) indicate that herbicide-organoclay complexes expanded upon sorption of the herbicide. SAz-HDTMA, after saturation with the herbicides, had the largest $\mathrm{d}_{001}$ expansion, increasing from 2.4 to $3.8 \mathrm{~nm}$, and $3.7 \mathrm{~nm}$ for bentazon and dicamba, respectively, whereas SAz-ODA only increased from 3.2 to $3.5 \mathrm{~nm}$ and $3.6 \mathrm{~nm}$, respectively. The different sorption capacities for these herbicides and the resulting basal spacing expansion can be related to the initial interlayer arrangement of the alkylammonium cation in these clays, and the molecular size of the corresponding herbicide. In general, basal spacing expansion as a result of the herbicide exposure confirms the interlayer sorption of the two herbicides in both organoclays.

Table 2. Amount of herbicide sorbed and basal spacings $\left(d_{001}\right)$ values of the $\mathrm{OCl}$-herbicide complexes.

\begin{tabular}{lccccc}
\hline & \multicolumn{2}{c}{ Bentazon } & & \multicolumn{2}{c}{ Dicamba } \\
\cline { 2 - 3 } Organoclay & Bentazon sorbed & $\mathbf{d}_{001}$ & & Dicamba sorbed & $\mathbf{d}_{001}$ \\
\hline & $\mathrm{mmol} \mathrm{kg}^{-1}$ & $\mathrm{~nm}$ & & mmol kg $^{-1}$ & $\mathrm{~nm}$ \\
SAz-HDTMA & 960 & 3.8 & & 856 & 3.7 \\
SAz-ODA & 666 & 3.5 & & 775 & 3.6 \\
\hline
\end{tabular}

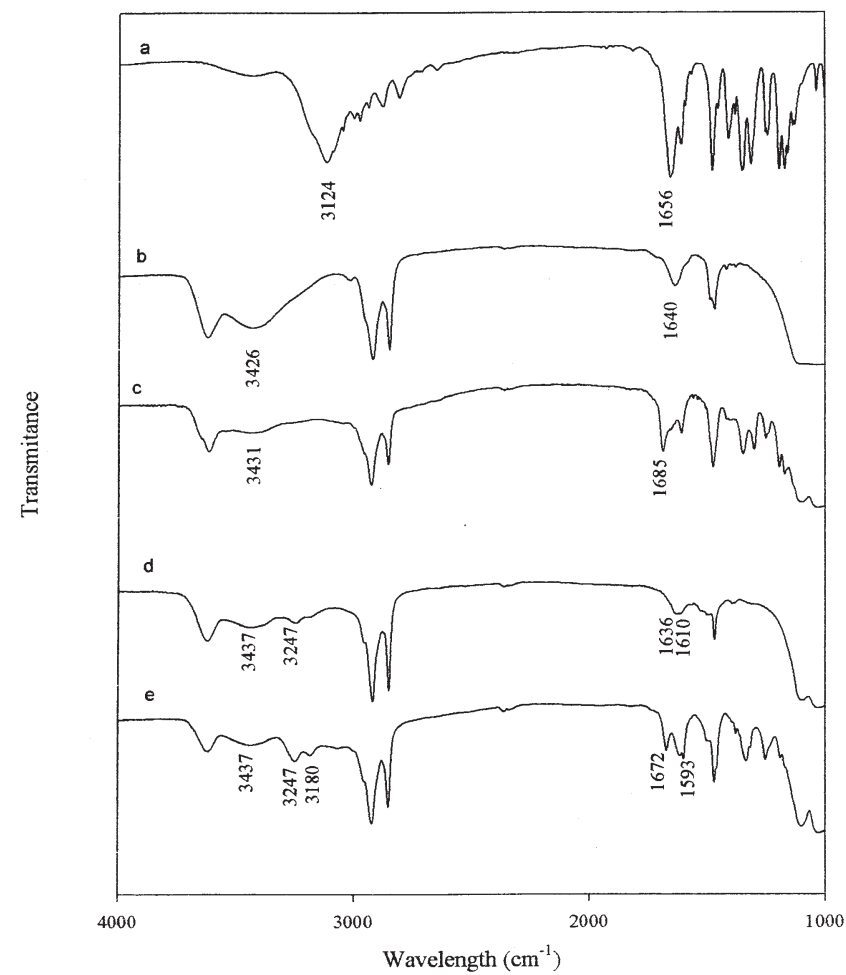

Fig. 1. Fourier transform infrared spectra of: bentazon (a), SAzHDTMA (b), SAz-HDTMA + bentazon (c), SAz-ODA (d), and SAz-ODA + bentazon (e).

Fourier transfer infrared spectra of pure herbicides, organoclays and organoclay-herbicide complexes are shown in Fig. 1 and 2. The FTIR band assignments in the following text are in accordance with Bellamy (1980). Figures 1 and 2 show that some of the bands occurred at the same frequency as in pure compound, while other bands were slightly shifted and some new bands appeared. For instance, organoclay spectra in Fig. 1b and d, and $2 \mathrm{~b}$ and $\mathrm{d}$, show differences in the $\mathrm{OH}$ and $\mathrm{NH}$ regions. SAz-HDTMA (Fig. 1b and 2b) shows bands at 3426 and $1640 \mathrm{~cm}^{-1}\left(v_{\mathrm{OH}}\right.$ and $\left.\delta_{\mathrm{OH}}\right)$ corresponding to molecular water that does not appear in SAz-ODA (Fig. 1d and 2d). SAz-ODA has bands at 3437 and $1636 \mathrm{~cm}^{-1}$ corresponding to the free $\mathrm{NH}$ groups of the primary alkylammonium (a little amount of molecular water can be included in these frequencies), in addition to weak bands at 3247 and $1610 \mathrm{~cm}^{-1}$ arising from $\mathrm{NH}$ bonded to basal oxygen atoms of the layer. Although the organic clays were washed with aqueous ethanol to remove all octadecylamine, washing may have been incomplete and there is a possibility that SAz-ODA may have contained both octadecylammonium and octadecylamine.

The differences in organoclays are related to the structure and saturation level of the alkylammonium cations. The long linear chain of the primary alkylammonium resulted in a more compact packing of those cations in the interlayer, creating a highly hydrophobic organic layer, which can prevent water intake. In contrast, the asymmetric structure of the quaternary alkylammonium, as well as its lower saturation level, leaves some polar room between the groups that can be occu- 


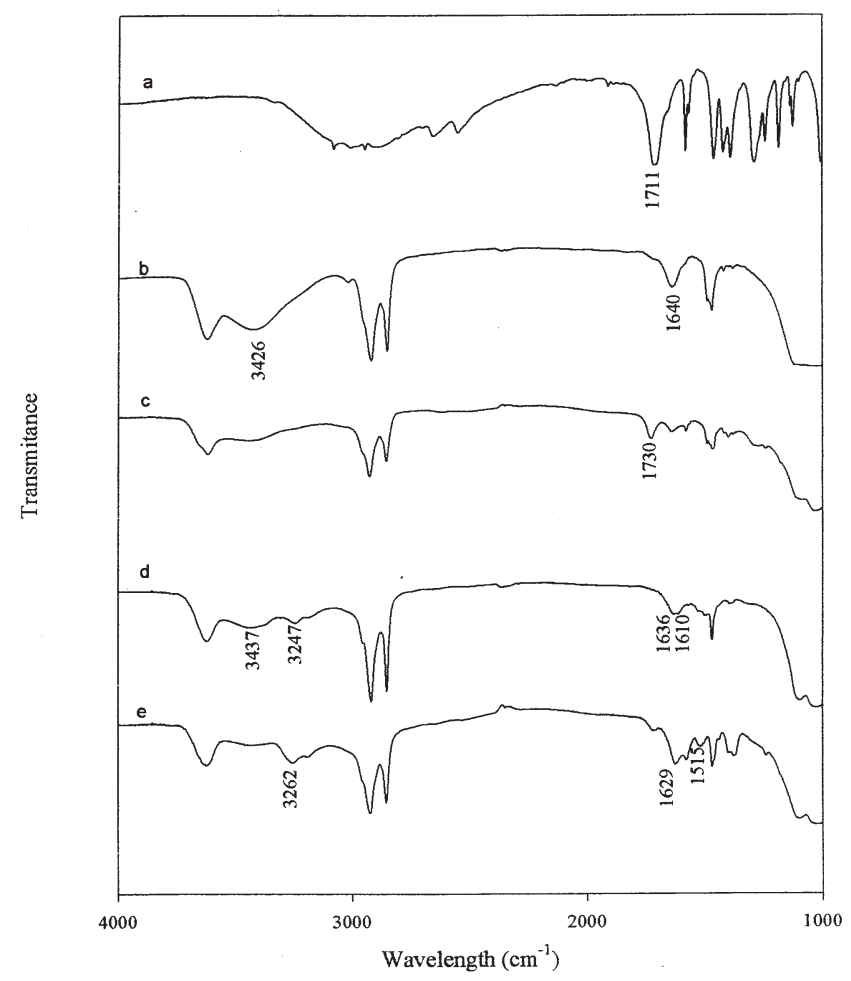

Fig. 2. Fourier transform infrared spectra of: dicamba (a), SAzHDTMA (b), SAz-HDTMA + dicamba (c), SAz-ODA (d), and SAz-ODA + dicamba (e).

pied by water molecules, probably associated with basal oxygens of the clay network or to residual inorganic cations.

The main feature of bentazon-SAz-HDTMA (Fig. 1c) complex is the near absence of bands 3426 and 1640 $\mathrm{cm}^{-1}$, indicating the displacement of the initial water molecules by bentazon. It appears bentazon is retained in monomeric form, as deduced from dissipation of the strong band of bonded $\mathrm{NH}$ at $3124 \mathrm{~cm}^{-1}$ and the shifting of the $\nu_{\mathrm{C}=\mathrm{O}}$ from $1656 \mathrm{~cm}^{-1}$ to higher frequency, 1685 $\mathrm{cm}^{-1}$, which indicates the rupture of the intermolecular bond (bentazon-NH-O $=\mathrm{C}-$ bentazon) between bentazon molecules in the pure compound. The small band at $3431 \mathrm{~cm}^{-1}$ suggests a weak polar interaction between bentazon $\mathrm{NH}$ with the basal oxygen atoms substituting the water molecules released. The retention of bentazon by SAz-HDTMA can be mainly attributed to the hydrophobic interaction between the bulky herbicide molecule and the alkylchains of the quaternary cation. This mechanism supports the reversibility observed in the sorption-desorption isotherms. These results are very similar to those reported by Celis et al. (2002) for the sorption of picloram on SAz-HDTMA, in which case additional interactions between the- $\mathrm{NH}_{2}$ group of the herbicide and the clay surface were involved.

In the case of bentazon-SAz-ODA complexes (Fig. $1 \mathrm{e})$, the increase in the intensities of bands at 3247 and $3180 \mathrm{~cm}^{-1}$ suggest the implication of the $\mathrm{NH}$ groups of the $\mathrm{OCl}$ in $\mathrm{H}$ bonding. This is supported because the initial $\nu_{\mathrm{C}=\mathrm{O}}$ bond of bentazon at $1656 \mathrm{~cm}^{-1}$ (Fig. 1a) splits into two bands in the bentazon-SAz-ODA complex (Fig. 1e) at 1672 and $1593 \mathrm{~cm}^{-1}$. The $1593 \mathrm{~cm}^{-1}$ band would correspond to $v_{\mathrm{C}=\mathrm{O}}$ strongly bonded through $\mathrm{H}$ bond to the $\mathrm{NH}$ group of the alkylammonium. The band at $1672 \mathrm{~cm}^{-1}$ implies the existence of some monomeric species retained in the paraffinic layer of the primary alkylammonium by weak hydrophobic interactions. Therefore, in this case two types of interaction are involved, hydrophobic interactions and strong polar $\mathrm{H}$ bonds. The strong polar interactions between $v_{\mathrm{C}=\mathrm{O}}$ of bentazone and the amino group of the alkylammonium would be responsible of the significant hysteresis observed in the sorption-desorption isotherms. Celis et al. (2002), found a similar behavior in sorption of picloram on SAz-ODA, but in that case, interactions between the ionized- $\mathrm{COO}^{-}$group of picloram and the interlayer primary alkylammonium of the organoclays were suggested.

The FTIR spectra of dicamba interactions with HDTMA and ODA are shown in Fig. 2. The band at $1730 \mathrm{~cm}^{-1}$ for dicamba-SAz-HDTMA was assigned to the $\mathrm{C}=\mathrm{O}$ strectching vibration of the protonated carboxylic group of dicamba and indicates that sorption involved the undissociated form of dicamba. In addition, a shift of $v_{\mathrm{C}=\mathrm{O}}$ of the carboxylic group from 1711 to 1730 $\mathrm{cm}^{-1}$ also suggests the presence of monomeric molecules in an undissociated form (Zhao et al., 1996). This mechanism supports the reversibility observed in the sorptiondesorption isotherms.

In the case of ODA, a strong diminution of the free $\nu_{\mathrm{N}-\mathrm{H}}$ at $3437 \mathrm{~cm}^{-1}$ is observed, together with an increase of the bonded $\nu_{\mathrm{N}-\mathrm{H}}$ at $3262 \mathrm{~cm}^{-1}$, suggesting the implication in $\mathrm{H}$ bonding. Moreover, the carboxylic $v_{\mathrm{C}=\mathrm{O}}$ at $1711 \mathrm{~cm}^{-1}$ in the pure herbicide practically disappeared, showing that most of dicamba is $\mathrm{H}$ bonded to $\mathrm{NH}$ group of the interlayer alkylammonium, and the bond is displaced at lower frequencies at $1629 \mathrm{~cm}^{-1}$. It is interesting to point out that a new band appears at $1515 \mathrm{~cm}^{-1}$, which can be assigned to the stretching of $\mathrm{C}-\mathrm{O}$ in a dissociated carboxylic group. This dissociation of some dicamba molecules can be induced by a strong elestroctatic interaction of the anionic form with the positively charged alkylammonium cations. All the FTIR features described above, suggest that in addition to hydrophobic interactions, dicamba is sorbed by strong polar and ionic bonding, which in turn explains the hysteresis observed for the sorption-desorption process.

In summary, the results of this work show that the modification of montmorillonite with alkylammonium cations resulted in interlayered organoclays with high sorptive properties for acidic herbicides. X-ray diffraction and FTIR studies indicate interlayer sorption of bentazon and dicamba in SAz-HTDMA and SAz-ODA and weak interactions between the herbicide molecules and SAz-HDTMA that are in agreement with the high reversibility observed in the sorption-desorption isotherms. For SAz-ODA, H bonding contributed to increase the strength of interaction, which in turn resulted in decreased desorption. Environmental implications for these results suggest that organoclays can be used to remove this type of pollutant from water or soils or as support for the slow release formulation of anionic or acidic acids. 


\section{Acknowledgments}

This work has been partially financed by Spanish CICYT through Project AMB 96-0445-CO2-01 by the Predoctoral Fellowship of PFPI of the Spanish MEC. This research was done by M.J. Carrizosa in the USDA-ARS Laboratory at the Department of Soil Water and Climate, University of Minnesota, and at IRNAS-CSIC laboratory.

\section{References}

Aguer, J.P., M.J. Calderon, M.C. Hermosin, and J. Cornejo. 2000. Fenuron sorption by homoionic natural and modified smectites. J. Environ. Sci. Health. B35:279-296.

Bellamy, L.J. 1980. The infrared spectra of complex molecules (Vol. I) Chapman and May (ed.), London and New York.

Boyd, S.A., J.F. Lee, M.M. Mortland, and C.T. Chiou. 1988. Sorption characteristics of organic compounds on hexadecyltrimethylammonium-smectite. Soil Sci. Soc. Am. J. 52:652-657.

Carrizosa, M.J., M.J. Calderon, M.C. Hermosin, and J. Cornejo. 2000. Organoclay as sorbent and carrier of the herbicide bentazone. Sci. Total Environ. 247:285-293.

Carrizosa, M.J., W.C. Koskinen, M.C. Hermosin, and J. Cornejo. 2001. Dicamba adsorption-desorption on organoclays. Appl. Clay Sci. 18:223-231.

Celis, R., W.C. Koskinen, M.J. Carrizosa, A. Cecchi, M.A. Ulibarri, I. Pavlovic, and M.C. Hermosin. 1999. Sorption of ionizable pesticide imazamox by organic clay and organohydrotalcites. J. Environ. Sci. Health B34:929-941.
Celis, R., M.C. Hermosin, M.J. Carrizosa, and J. Cornejo. 2002. Clayherbicide complexes to retard picloram leaching in soil. Int. J. Environ. Anal. Chem. 82:503-517.

Hermosin, M.C., and J. Cornejo. 1992. Removing 2,4-D from water by organo-clays. Chemosphere 24:1493-1503.

Hermosin, M.C., and J. Cornejo. 1993. Binding mechanism of 2,4-dichlorophenoxy-acetic acid by organoclays. J. Environ. Qual. 22:325331.

Hermosin, M.C., A. Crabb, and J. Cornejo. 1995. Sorption capacity of organo-clays for anionic and polar organic contaminants. Fresenius Envir. Bull. 4:514-519.

Lee, J.F., J.R. Crum, and S.A. Boyd. 1989. Enhanced retention of organic contaminants by soils exchanged with organic cations. Environ. Sci. Technol. 23:1365-1372.

Pantani, O., S. Dousset, H. Schiaron, and P. Fusi. 1997. Adsorption of isoproturon on homoionic clays. Chemosphere 35:2619-2626.

Socias-Viciana, M.M., M.C. Hermosin, and J. Cornejo. 1998. Removing prometone from water by clays and organo clays. Chemosphere 37:301-318.

Van Olphen, H., and J.J. Fripiat. 1979. Data handbook for clay minerals and other non-metalic minerals. OECD and Clay Mineral Society. Pergamon Press, Oxford.

Worthing, C.R., and R.J. Hance. 1991. The pesticide manual. BCPC, Surrey, UK.

Xu, S.G., G. Sheng, and S.A. Boyd. 1997. Use of organoclays in pollution abatement. Adv. Agron. 59:25-62.

Zhao, H., W.F. Jaynes, and G.F. Vance. 1996. Sorption of the ionizable organic compound, dicamba (3,6-dichloro-2-methoxy benzoic acid), by organo-clays. Chemosphere 33:2089-2100. 